diagnosis and that the resulting delay may have serious consequences. The frequency with which these mistakes are made suggest that a very thorough examination should be carried out whenever articles are alleged to have been inhaled or swallowed, and that when the object is not found the bronchoscope and cesophagoscope should be employed. The more modern methods described above, which are not difficult to use, are far superior to the obsolete bougie, probang, or coin. catcher.

In conclusion, there is no class of case in medicine or surgery which gives greater satisfaction to those concerned than the successful removal of a foreign body which imperils the life of a patient or causes a long period of ill-health, resulting too often in death.

\section{A CASE OF CONGENITAL ATRESIA OF THE BILE-DUCTS.*}

BF STANLEY WYARD, M.D. LOND., M.R.C.P. LOND., PATHOLOGIST TO THE VICTORIA HOSPITAL FOR CHILDREN, CHELSEA, S.W.

ALTHOUGH cases of this disease are not of extreme rarity, few records have been published on the pathological-more especially the microscopical -aiterations that occur. In view of the fact that such details are much needed ${ }^{1}$ I have called attention to this case.

The patient, a female infant, first came under observation in the out-patient department of the Victoria Hospital for Children in April, 1913, when aged 4 months. She had been jaundiced for the past three months ; the motions were pale, and the urine stained her napkins. A rash was present, especially about the buttocks. Snuffles were observed. The liver was then much enlarged, but the spleen could not be felt. In July, 1913, she was admitted as an in-patient. The history obtained showed that at birth her colour was normal, but when three weeks old she became yellow. The motions were clay coloured from that time onward. The degree of jaundice varied from time to time, but was much more marked during the few weeks previous. After separation of the cord the umbilicus healed well. Feeding was artificial, with cows' milk and barley water. She vomited frequently from birth, and there had been profuse sweating for the past two weeks. The mother had had five other children who were all well, and one miscarriage six years ago. The condition on admission was fairly good, and she was fairly well developed. Jaundice was marked, the skin being deep yellow and the sclerotics very yellow. No abnormality was found in the heart or lungs. The liver was enlarged and reached two fingerbreadths below the costal margin. A hernia had occurred through the umbilicus. The temperature was normal. No alteration was noticed during the next 14 days, and she was then discharged.

In October a little free fluid was found in the peritoneal cavity, and afterwards it gradually increased in amount until December, when she was again admitted to the ward. The jaundice was now very intense. The enormously distended abdomen caused considerable respiratory distress. Numerous distended veins were apparent in its anterior wall, and in them the blood flowed upwards. The peritoneal cavity contained much free fluid and the liver was felt to be enlarged, extending three fingers-breadth below the oostal margin. The spleen, also much enlarged, extended the same distance on the other side. The ribs showed marked beading. Very numerous râles and crepitations were heard over the right side of the chest in front, but none elsewhere. The heart gave no abnormal physical signs. The anterior fontanelle was very large-enough to have admitted five fingers. No œdema was anywhere found. On the following day the infant was much worse, and râles were heard all over the

* Shown before the West London Medico-Chirurgical Society on Jan. 16th, 1914 . chest. The temperature rose from normal to $101 \cdot 6^{\circ} \mathrm{k}$., and on the morning of the third day to $103^{\circ}$, when death occurred.

Post-mortem examination.-A deeply jaundiced infant, extremely emaciated. The abdomen was very distended, with large veins coursing over it. On opening the belly a large quantity of bile-stained fluid escaped. The alimentary canal presented no abnormal appearances. The mesenteric glands were enlarged and dark-coloured. The liver weighed $12 \mathrm{oz}$. The surface was nodular, the nodules being small. It was firm in consistence and tough on section. Its colour was a very deep green. A cut surface presented a mottled appearance. The strands of fibrous tissue stood out plainly, somewhat paler than the rest of the substance. They cut the organ up into small islets, about $1 \mathrm{~mm}$. in diameter. These were circular, the circumference being a deep green colour, while the centre was paler and yellowish. The fibrous tissue was much greater in amount at the hilum where the strands were of great thickness, gradually becoming narrower as the periphery of the organ was reached. The hepatic ducts were completely obliterated, and at a very short distance from their junction faded away into the connective tissue of the gastro-hepatic omentum, so that they could not be traced to the duodenum; not even a fibrous cord remaining to represent them. The gall-bladder was merely a fibrous cord deeply buried in the liver substance. Like the commor. bile-duct, the cystic duct was lost in the gastro-hepatic omentum, and could not be traced to its junction with the common bile-duct. The vessels, hepatic artery and portal vein, were normal. The spleen weighed $3 \mathrm{oz}$. It was firm in consistence, but presented no abnormality on section. The splenic vessels were patent and healthy. The pancreas, kidneys, and adrenals were all normal. There was very marked œdema of the retroperitoneal and perirenal tissues. Both lungs were deeply congested and œdematous. The heart was normal.

Mioroscopic examination.-The organ is extremely and markedly fibrosed. The normal lobulation is entirely lost and the hepatic cells show all stages of degeneration-all that is left of them in some places being a granular débris. Those which retain some vitality are generally crowded with small brownish granules of bile pigment. There is a slight degree of fatty degeneration. Some of the cells contain minute fatty droplets (demonstrated by Sharlach $R$ ), but in no case is any great distension of the cell brought about in this way. The fatty degeneration is confined to the hepatic cells and cannot be found in the cells of the pseudo-bile canaliculi. The nuclei are round and large as a rule, though some have become irregular in shape. They do not take up much stain and are poor in chromatin. There is no evidence of proliferation of the liver cells. Towards the centre of the organ the cells are somewhat healthier in appearance and the deposit of pigment less.

Strands of fibrous tissue are present throughout the organ, forming a fine network, in the meshes of which are small isolated groups of liver cells. The individual cells are also surrounded and separated from each other by fine fibrils of connective tissue, so that a mixed condition i present, a perilobular and a pericellular cirrhosis coexisting Towards the periphery some of the fibrous-tissue cells are younger in appearance and show some evidence of active proliferation, but towards the centre of the organ they are older and show no such signs. The process has, however reached an almost stationary stage. There is no active inflammatory change nor any leucocytic infiltration. In the fibrous tissue very numerous mast cells can be demonstrated by Pappenheim's methyl green pyronin stain or by polychrome methylene blue. They vary much in shape, contain somewhat deeply staining nuclei which are eccentric in position, and show in their cytoplasm closely packed, coarse, orange-red granules. Generally they are seen on or very near a vessel-wall. They are never seen among the liver cells proper. They occur in small numbers near the hilum, becoming numerous towards the periphery where in some sections great numbers are seen. No plasma cells have been found. There is very little subcapsular fibrosis. The vessels appear throughout normal. The finer bile-ducts - those at the periphery of the organ-are patent and many are filled with inspissated bile. Pseudo-bile canaliculi are present and are often a feature of the part under examination. As the hilum is approached they increase in number while the bile-ducts disappear, and within a short distance H 2 
of the hilum none can be found, nor any bile. Often the fibrous tissue can be seen surrounding and cutting off groups or columns of liver cells from the periphery of a lobule, which then present all the appearances of pseudo-bile canaliculi. The wall of the gall-bladder is much thickened and composed of young connective tissue cells. It is very vascular, and contains several large vessels-arteries and veins-the walls of which are normal. The cavity remains, though very small, and is lined by a healthy endothelium of cubical cells. The round ligament presents no abnormality.

Upon the etiology of this interesting condition the present case throws no light-syphilis, as usual, appears to play no part, and no hereditary influence is shown. On turniug, however, to its pathogeny one or two points may be considered. Dr. Rolleston believes that the fault is with the mother, that from her a toxin is derived which, passing through the placenta and its vessels, reaches the liver, where it causes a cirrhosis. The primary fœtal condition is thus an irritative change in the liver. But some of the blood passes on by the ductus venosus into the general circulation. Later it returns by the hepatic artery to the liver. Here the toxin is excreted in the bile and sets up a descending cholangitis. He also suggests that the toxin may be analogous in its action to toluylenediamine. The action of toluylenediamine has been very fully described by Hunter. ${ }^{3}$ He finds that animals under the influence of this drug suffer from a descending cholangitis involving primarily the bile-ducts at their origin. Later the whole of the bile radicles and the smaller ducts are simultaneously affected. Sometimes the process stops here, though in other cases the catarrh may extend to the common bileduct and even to the duodenum itself. The point $I$ wish chiefly to emphasise is that the inflammation affects first and with the greatest intensity the finest bile capillaries.

From this description I think it fair to conclude that the excretion of any other irritating substance into the bile would produce a cholangitis affecting first and chiefly the smallest bile channels. But in the case under consideration the exact reverse holds-the finest bile capillaries are patent and show less affection than the largest ressels. Prima facie, then, an ascending cholangitis would appear the more likely lesion. Is this possible? A gastroenteric inflammation travelling from the duodenum up along the common bile-duct would be capable of producing all the appearances found here. The inflammation would be most intense the nearer it was to the duodenum, and diminish in intensity in direct proportion to its distance therefrom or to its approach to the periphery of the liver. Furthermore, the resistance of the patient's body may to some extent limit the spread. The post-mortem appearances indicate a stationary or almost stationary condition; and also the fact that life was prolonged for 12 months points to some such protective reaction.

The existence of a toxin is, at the best, purely conjectural; its presence or absence cannot be demonstrated. May it not, then, be supposed to be a constituent of a pathological liquor amnii? It is known that the foetus in utero ingests quantities of this liquid which might thus reach the duodenum. The origin of such a body in the liquor amnii would appear to be maternal, passing through the placenta as do some of the normal constituents of the liquid. ${ }^{5}$ It is difficult to imagine any process by which the foetus could produce in utero a toxin inimical to itself. The presence of such a pre-natal affection would, moreover, lay the patient more freely open to the post.natal attack of other pathogenic agents.

Cirrhosis is in adult life probably due to a toxin elaborated in the gastro-intestinal tract. ${ }^{6}$ At the same time Lissaner ${ }^{7}$ finds that cirrhosis of the liver can be produced by ligation of the common bile-duct or its branches without other cause. The changes produced are, in his opinion, identical with those found in human cirrhosis. But he also finds that experimental data prove the change following ligature of the duct to be largely influenced by infective processes. Thus in this case it seems possible that the same agent which by direct extension causes an ascending cholangitis, at the same time, by absorption and circulation in the blood through the liver, initiates a cirrhosis which is aided and increased later by the obliteration of the ducts.

Thomson, ${ }^{8}$ in his original paper on this condi. tion, believed that a necessary factor in its pathogeny was a maldevelopment "by which the ducts were narrowed; while the imposition of an inflammatory swelling on such a developmental constriction produced complete obstruction. In a later article ${ }^{9}$ this view, though not contradicted, was dismissed as having nothing in its favour. Yet later ${ }^{10}$ he revives it and states that it must be held to play a part. The cirrhosis he considers secondary to the biliary obstruction. The present case adds no data on either side.

In the clinical course and appearances of this case nothing is remarkable except the duration of life. Hitherto it has been said that no child proved to have this complaint has ever lived 11 months, ${ }^{11}$ whereas another month must now be added to that period. The average length of life is $2 \frac{1}{2}$ months. Finally, the development of ascites in this condition is rare. I have to thank Dr. J. W. Carr and Dr. A. C. D. Firth for the clinical notes of this case and for permission to use them.

Bibliography.-1. Thomson: Allbutt and Rolleston's System of Medicine, 1908, vol. iv, Part I., p. 104. 2. Rolleston. Diseases of the Liver, \&c., p 643. 3. Hunter. Wm. : The Action of Toluylenediamine Journal of Pathology and Bacteriology, vol. iii., 1896; Albutt and Rolleston's System of Medicine, 1908 vol iv. Part I., p. 41 et seq 4. Eden : A Manual of Midwifery, p. 39. 5. Jellett: A Short Manua of Midwifery. 6. Rolleston: Loc. cit., p. 195. 7. Lissauer, Max Quoted by Brit. Med. Jour., April 25th, 1914, p. 922 p. 8. Thomson Hdinburgh Medical Journal, vol. xxxrii., Part II., p. 73\%. 9. Thomson Allbutt and Rolleston's System of Medicine, 1897, vol. iv., p. 256 10. Ibid., 1908, vol. iv., Part I. 11. Thomson: Clinical Examination and Treatment of Sick Children, p. 173.

VACCINATION IN IRELAND.-The RegistrarGeneral for Ireland has recently issued a return dealing with the statistics of vaccination of children born in Ireland in 1912. It discloses a grave and growing neglect of vaccination. Of the total number of children born in 1912 it appears that only 66.3 per cent. have been successfully vaccinated; of the remainder, 3.3 per cent. were postponed on account of ill-health, 0.1 per cent. were insusceptible of vaccination, 57 per cent. died without being vaccinated, $3 \cdot 1$ per cent. were unaccounted for, and 21.5 per cent. were returned as defaulters. The disquieting factor is that the number of defaulters is increasing in ancelerated proportion. In 190582 per cent. were vaccinated, as against 66.3 per cent. in 1912 . There is no doubt that the falling off in vaccination is due to the active eampaign against vaccination, for it is precisely in those districts where the campaign is most active that the falling off is most marked. In Leinster the vaccinations represented only 45.8 per cent. of the births registered. In county Wexford, where the campaign began, there were only 301 children successfully vaccinated, while there were 1700 defaulters, and in the neighbouring county of Wicklow there were 464 successful vaccinations and 587 defaulters. A grave responsibility. rests with the Local Government Board for permitting the boards of guardians to connive at the constant breaches of the vaccination laws. 